able outcomes; severe disability, vegetative state, or death were unfavourable.

We used the $\chi^{2}$ test to compare the unfavourable outcome rates of the two units and the time periods (up to or after 1995), and we used logistic regression to include age and presenting condition (according to the World Federation of Neurological Surgeons' (WFNS) grading $^{4}$ ).

The rate of an unfavourable outcome was $35 \%$ in Newcastle and 19\% in Nottingham. This difference was significant $(\mathrm{P}<0.0001)$. The results in Newcastle worsened over time. These differences disappeared when the effects of age and presenting condition were included. Newcastle operated a less selective admissions policy than Nottingham because it did not have the deficiency of beds that Nottingham had. Between 1992 and 1998 Newcastle became progressively less selective, admitting more patients with a poor WFNS grading and more older patients. The table shows the independent effects of age, WFNS grade, and neurosurgery unit.

\section{Comment}

The observed difference in outcomes between the units does not necessarily reflect the quality of care given, but rather it can be explained by case mix and the impact of the availability of resources on admission criteria. This only became evident through careful and specifically funded audit. The use of the crude results to guide clinical governance and policy making would have been highly pernicious.

It is easy to apply methods of performance analysis to medicine. The problems are not a lack of such methods but rather a lack of appropriate processes for collecting data and a poor understanding of likely confounding factors and how to measure them. Political motivation leads to pressure to produce easily accessible results. This approach is considerably worse than doing nothing and should be resisted. Collection of data on factors that may influence outcome is a prerequisite of the statistical comparison of results between units. These include, but are not restricted to, the quality of care given. Had Newcastle come under pressure from clinical governance to improve results without this being appreciated, the service it offers would have been compromised.

We thank R P Sengupta, C J Gerber, A Jenkins, A Gholkar, N V Todd, B White, P Byrne, I Robertson, R Ashpole, J Firth, J Stevens, and P Moody for their care of some of the patients in the study.

Contributors: PM conceived the study and wrote the paper. BAG maintained the database and did the statistical analysis. TH and ADM conducted the study in Nottingham and Newcastle respectively. PM is guarantor for the paper.

Funding: The study was funded by grants from the Northern Brainwave Trust and the Newcastle Neurosurgery Foundation. Competing interests: None declared

Ethical approval: At the time of our study, audits did not require approval from ethics committees but did require registration with the Data Protection Agency, a requirement we fulfilled.

1 Sahs AL. Aneurysmal subarachnoid haemorrhage. Report of the cooperative study. Baltimore, MA: Urban \& Schwarzenberg, 1981.

2 Nelson MJ. Safe neurosurgery 2000. London: Society of British Neurological Surgeons, 1999

Jennett B, Bond M. Assessment of outcome after severe brain damage. Lancet $1975 ; 1: 480-4$.

4 Report of World Federation of Neurological Surgeons Committee on a Universal Subarachnoid Hemorrhage Grading Scale. I Neurosurg 1988;68:985-6.

(Accepted 15 January 2004)

doi 10.1136/bmj.38084.592639.AE

\title{
Hospital mortality league tables: influence of place of death
}

Valerie Seagroatt, Michael J Goldacre

League tables that rank hospitals according to their death rates are now regularly published in England. ${ }^{1-3}$ The rationale for publication is that differences in death rates may indicate differences in quality of hospital care. Yet a hospital is not only a place for treatment and cure, it is also a place for care of the dying. Currently 55\% of all deaths in England occur in NHS hospitals. ${ }^{4}$ Provision and use of different facilities for the care of the dying varies geographically. ${ }^{4}$ We investigated how this variation might influence the scale and ranking of hospital death rates.

\section{Method and results}

Dr Foster Ltd has published in-hospital death rates for 167 acute NHS hospital trusts (hereafter termed hospitals) in England over the three year period April 1999 to March 2002..$^{1-5}$ The denominators were the number of episodes of admission to each hospital, as recorded in the hospital episode statistics system, and the numerators were the number of these episodes that ended in death. The rates were standardised by age, sex, source of admission, length of stay, and diagnosis, expressed relative to the rate for all hospitals combined, multiplied by 100, and termed hospital standardised mortality ratios (HSMRs). The report highlighted 15 hospitals with the highest and 15 with the lowest mortality ratios. The investigators showed that the probability of these being in the top or bottom 15 was not attributable to random error. We used data on these hospitals for our analysis but excluded London hospitals because of difficulty in determining their catchment areas. This left 11 hospitals with high ratios and nine with low ratios.

$$
\text { A table showing rates for places of death is on bmj.com }
$$

This article was posted on bmi.com on 29 March 2004: http://bmj.com/ cgi/doi/10.1136/bmj.38058.517118.47
Unit of Health-Care Epidemiology, Department of Public Health, University of Oxford, Oxford OX3 7LF

Valerie Seagroatt university research lecturer

Michael J Goldacre professor of public health

Correspondence to: V Seagroatt valerie.seagroatt@ valerie.seagroat

BMJ 2004;328:1235-6 


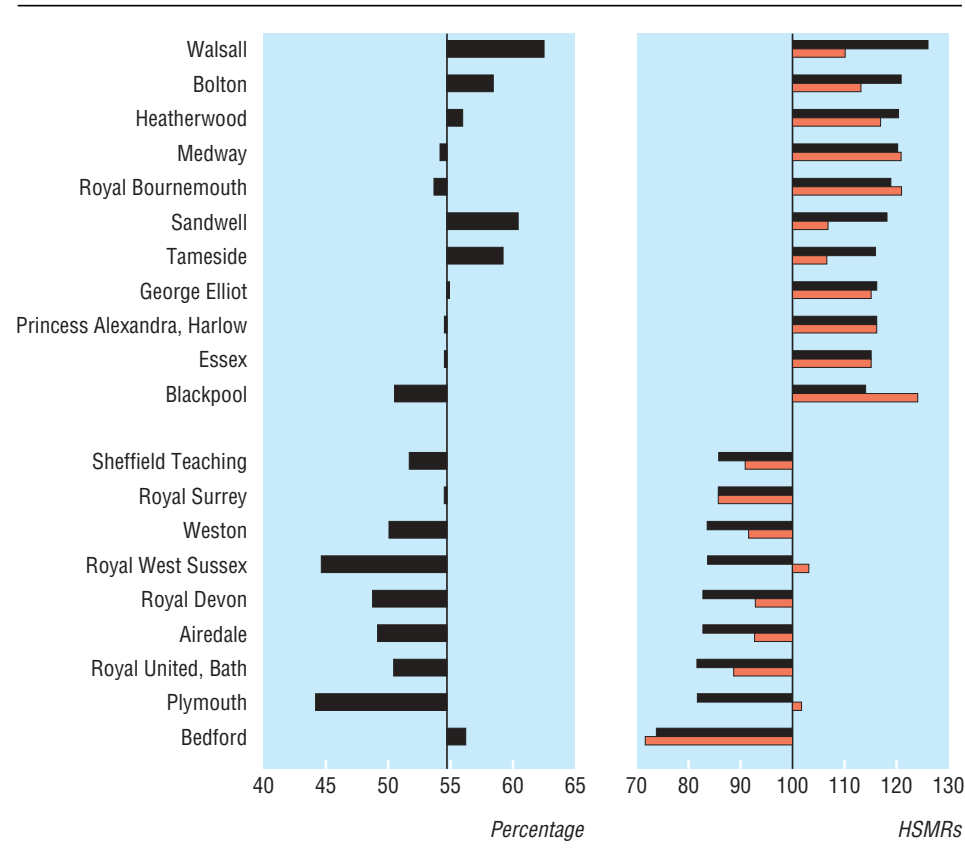

Percentages of deaths occurring in NHS hospitals for catchment areas of hospitals (vertical line is percentage for England) and hospital standardised mortality ratios (HSMRs) as published (black) and after adjustment (red). Hospitals are plotted in ranking order of published HSMRs ${ }^{1}$ the differences between hospitals in their in-hospital death rates. Calculation of in-hospital death rates, aggregated across a wide clinical spectrum, including a mixture of admissions for treatment, cure, and palliative and terminal care, gives rates that are difficult to interpret as quality measures.

We thank Pamela Evans for typing the manuscript.

Contributors: MJG proposed the study; VS analysed the data. Both designed the study, wrote the manuscript, and will act as guarantors.

Funding: VS is funded by the Research and Development Directorate of the Department of Health and Social Care (South). MJG holds a grant from the Department of Health for the Oxford site of the National Centre for Health Outcomes Development (NCHOD). The funding body had no role in the design or writing of the work covered by this report.

Competing interests: None declared.

Ethical approval: Not needed.

1 The good hospital guide. 6 April 2003. www.timesonline.co.uk (accessed 1 Aug 2003).

Ellis R. The Good Hospital Guide 2002. A deadly lottery: you are twice as likely to die at the worst hospitals. Mail on Sunday 2002 March 10.

Jacobson B, Mindell J, McKee M. Hospital mortality league tables. BMJ 2003;326:777-8.

4 Review of the registrar general on deaths in England and Wales, 2000. Norwich: Stationery Office, 2000. (DH1, No 33.)

5 Hospital guide. www.drfoster.co.uk (accessed 1 Aug 2003).

(Accepted 17 December 2003)

doi $10.1136 /$ bmj. 38058.517118 .47

Statistics on place of death (NHS hospital, hospice, home, etc) of residents of different areas are published routinely. ${ }^{4}$ These were available for two of the three years on which the published hospital league tables were based (1999 and 2000). We used hospital episode statistics to identify the individual health authorities that corresponded most closely to the catchment area of the 20 selected hospitals, and we used the published figures on place of death to calculate the percentage of deaths of residents of each catchment area that occurred in NHS hospitals. We then adjusted the published HSMRs to allow for geographic differences in the percentages of deaths occurring in hospital in the hospitals' catchment areas. We did this by scaling down the values when proportionately more deaths of residents occurred in NHS hospitals compared with England as a whole and scaling up those when proportionately fewer deaths occurred in hospital. For instance, for every 1000 deaths of residents of Walsall Health Authority, on average 623 occurred in NHS hospitals. For England overall, the average was 546. We reduced the published HSMR for the Walsall hospitals, 126 , by the scaling factor $0.88(546 / 623)$, which gave an adjusted HSMR of 110 .

The percentages of deaths of residents of health authorities that occurred in NHS hospitals varied from less than $45 \%$ in Plymouth and West Sussex to over $60 \%$ in Walsall and Sandwell (figure, and see table on bmj.com). In most cases the adjustment brought the HSMRs closer together and closer to 100 . It also changed the rankings.

\section{Comment}

Geographical differences in the provision of facilities for the dying are a plausible explanation for some of

\section{Corrections and clarifications}

Preventing childhood obesity by reducing consumption of carbonated drinks: cluster randomised controlled trial Two errors crept into table 2 of the full version (on bmj.com only) of this paper by Janet James and colleagues (22 May, p 1237). Firstly, the parentheses should be around the second set of values (which are the percentages) not the first set of values (which are the numbers). Secondly, the control girls consumed 95 (not 5 ) glasses of carbonated drinks in three days. The authors also want to make clear that data in the table relate to overweight children who fall between the 91st and 98th centiles and to obese children above the 98th centile.

Minerva

Minerva was reminded by a reader that she had forgotten to insert a reference for one of the items in the issue of 24 April ( $p$ 1024). The reference for the final item (about fatigue in patients with primary biliary cirrhosis) is Gut 2004;53:587-92.

Length of patient's monologue, rate of completion, and relation to other components of the clinical encounter: observational intervention study in primary care In this Primary Care paper by Israel Rabinowitz and colleagues (28 February, pp 501-2), a misspelling of the surname of the second author (Rachel Luzzati) persisted to publication. There is only one " $\mathrm{t}$ " in Luzzati (not two). This has been corrected on bmj.com.

Integrating health care for mothers and children in refugee camps and at district level

The name of the first author in reference 8 was wrongly spelt in this Education and Debate article by Assad Hafeez and colleagues (3 April, pp 834-6). The correct spelling is Rahman. 